\title{
Effect of Inspiratory Absolute Humidity on Leak During NPPV
}

\author{
Yuri Fueda ${ }^{1, ~ *, ~ T a k u y a ~ K a t a o k a ~}{ }^{2}$, Fuka Matsuda ${ }^{2}$ \\ ${ }^{1}$ Department of Medical Engineering, Faculty of Health Sciences, Morinomiya University of Medical Sciences, Osaka, Japan \\ ${ }^{2}$ Department of Medical Engineering, Faculty of Health Sciences, Himeji Dokkyo University, Himeji, Japan \\ Email address: \\ yuri_fueda@morinomiya-u.ac.jp (Y. Fueda),k45014009@yahoo.co.jp (T. Kataoka),f45014015@yahoo.co.jp (F. Matsuda) \\ ${ }^{*}$ Corresponding author
}

\section{To cite this article:}

Yuri Fueda, Takuya Kataoka, Fuka Matsuda. Effect of Inspiratory Absolute Humidity on Leak During NPPV. International Journal of Biomedical Science and Engineering. Vol. 7, No. 1, 2019, pp. 16-19. doi: 10.11648/j.ijbse.20190701.13

Received: September 12, 2018; Accepted: May 27, 2019; Published: June 18, 2019

\begin{abstract}
Noninvasive ventilator connects a one-way circuit with leak and delivers inspired gas via the upper airway tract. A heated humidifier don't have to connect to contain heat and moisture exchange humidity in the upper airway functions. However, there are many case connecting a heated humidifier to be inadequate humidity in the upper airway. The purpose of this study was to clarify the influence of absolute humidity on leak and inspiratory positive airway pressure during noninvasive positive pressure ventilation. We connected respiratory machine, a heated humidifier and a model lung via two type circuits. One circuit was a single-limb breathing with an exhalation port and another was two- way circuits to distinguish the inspiratory from the expiratory via Y-piece. Two heated humidifiers were included in both inspiratory and expiratory circuits to simulate the physical lung. Relative humidity, temperature and flow rate were measured for 30 minutes. Absolute humidity was calculated using the Teten's equation and a gas state equation with relative humidity and temperature. In results, flow rate increased and absolute humidity decreased, when leak volume increased. We presumed that warmer humidified gas was discharged through the leak port with increasing flow rate to compensate leak. However, absolute humidity slightly was not associated with higher inspiratory positive airway pressure at the steady leak. We supposed that expiratory gas was not capable to discharge due to increasing flow rate and might be accumulated into the mask. The expired gas temperature accumulated in the mask might affect the inspired absolute humidity. Consequently, we are desirable to measure the inspired gas temperature and absolute humidity. In conclusion, absolute humidity would depend on leak during noninvasive positive pressure ventilation.
\end{abstract}

Keywords: NPPV, Leak, Absolute Humidity

\section{Introduction}

Noninvasive positive pressure ventilation (NPPV) via face mask has markedly increased over the past two decades [1]. NPPV have indicated effective for the patients, for instance respiratory failure, heart failure and sleep apnea syndrome [2-4]. Complications, such as sore throat, pharynx edema or the recurrent laryngeal nerve paralysis, get decreasing to support ventilation without the endotracheal intubation and tracheostomy. NPPV uses an open circuit design which is inherently leaky [5]. Therefore, NPPV change flow rate to compensate leak around the edge of the interface or through the mouth $[6,7]$.

When inspired gas passes through the upper airway during normal breathing, the gas is heated and humidified through the tracheal mucosa. The gas reaches $37^{\circ} \mathrm{C}$ and a relative humidity (RH) of $100 \%$ at the carina trachea. Inspired gas on NPPV also heats and humidifies to pass through the upper airway. Therefore, NPPV circuits don't have to include a heated humidifier on Clinical practice guideline [8]. However, the previous report showed that an absolute humidity (AH) less than $10 \mathrm{mg} / \mathrm{L}$ was associated with upper airway dryness in continuous positive airway pressure (CPAP) users [9]. The use of dry gases during nasal CPAP without humidification in healthy individuals significantly decreased nasal humidity [10]. Therefore, paramedical staff add heated humidifier in NPPV circuits corresponding to the patient's condition in clinical practice. Despite such a situation, the functions of 
many heated humidifiers are setting temperature and measuring real value, but not the humidity. It's important to estimate the humidity on NPPV to prevent from upper airway dryness. There has been little examination of the humidity in NPPV. One case study showed that increasing inspiratory positive airway pressure (IPAP) was associated with decreasing RH during NPPV $[9,11]$. RH is defined as ratio of the water vapor density to the saturation water vapor density. RH might be shown high ratio, even if the water contents are low. Therefore, we considered that the humidity needed to be shown by AH. The purpose of this study was to clarify the influence of AH on leak and IPAP during NPPV.

\section{Methods}

\subsection{Ventilation Settings}

NPPV ventilator, BiPAP Vision (Phillips Company, Andover, Massachusetts, USA), was used for our study. A lung model (Lung Simulator; SMS Technologies, Essex, UK) was used in this study. The compliance value and resistance of the model lung was adjusted to $50 \mathrm{~mL} / \mathrm{cmH}_{2} \mathrm{O}$ and $5 \mathrm{cmH}_{2} \mathrm{O} / \mathrm{L} / \mathrm{s}$, respectively. The ventilator settings were performed IPAP of 10, 15 and $20 \mathrm{cmH}_{2} \mathrm{O}$ following Holland et al. [11]. Expiratory positive airway pressure (EPAP), respiratory rate and inspiratory time were maintained at $5 \mathrm{cmH}_{2} \mathrm{O}, 12$ breaths/min and $1.7 \mathrm{~s}$, respectively. The humidifier (MR410 with MR210 water chamber, Fisher\&Paykel, Auckland, New Zealand) was heated passover humidifier, in which the air passes into the water chamber and picks up water vapor by free evaporation. The temperature of the water chamber was heated on a hot plate, the temperature of which can be regulated in steps. The humidifier with the water chamber was inserted in respiratory circuit in according to the manufacture's recommendations. We exchanged a water chamber every time to steady the temperature and the humidity prior to the start of the experiments. $\mathrm{RH}$, temperature and inspiratory flow rate were measured with VT Mobile Gas Flow Analyzer (Fluke Biomedical, USA) every minute for 30 minutes.

We performed two settings. Experimental setting 1 was shown in Figure 1a. NPPV generally use a single-limb breathing circuits with an exhalation port, which serves as a passive exhalation port for the patient. We simulated leak flow rate of 15, 60 and $80 \mathrm{~L} / \mathrm{min}$ and checked in BiPAP vision. Experimental setting 2 was shown in Figure 1b. We distinguished the inspiratory from the expiratory via Y-piece to measure flow rate and $\mathrm{AH}$ for inspiratory gas. We connected additionally two one-way valves in inspiratory and expiratory circuits to prevent backflow. The humidifier was included in both inspiratory and expiratory circuits to simulate the physiological lung. We changed the size of T-piece port after an exhalation port and simulated leak flow rate of $20,30,40$ and $60 \mathrm{~L} / \mathrm{min}$.

\subsection{Absolute Humidity (AH)}

The saturation vapor pressure with temperature was calculated using the Teten's equation [12]. The actual vapor pressure was calculated the saturation vapor pressure times RH by (1).

$$
e a(T)=6.1078 \times 10^{\frac{7.5 T}{(T+237.3)}} \times \frac{R H}{100}
$$

ea was the actual vapor pressure at temperature. $\mathrm{T}$ was temperature in degrees Celsius. $\mathrm{RH}$ was expressed in percent. For the calculation of $\mathrm{AH}$, an equation obtained by converting a gas state equation could be used. We calculated $\mathrm{AH}$ with the actual vapor pressure with (2). We showed measurement $\mathrm{AH}$ data in Figure 1.

$$
A H(T)=\frac{e a(T) \times 10^{2}}{8.31447 \times(T+273.15)} \times 18
$$

\subsection{Statistical Analysis}

The combinations of the ventilation settings were studied 3 times each. The data were expressed as the mean \pm standard deviation (S.D.). The results for all the tests were evaluated by one-way factorial analysis of variance (ANOVA), followed by Tukey-Kramer's protected least significant difference (PLSD) multiple comparison test to identify significant differences among multiple samples. Statistical significance was seen when the $\mathrm{p}$ value was less than 0.05 .

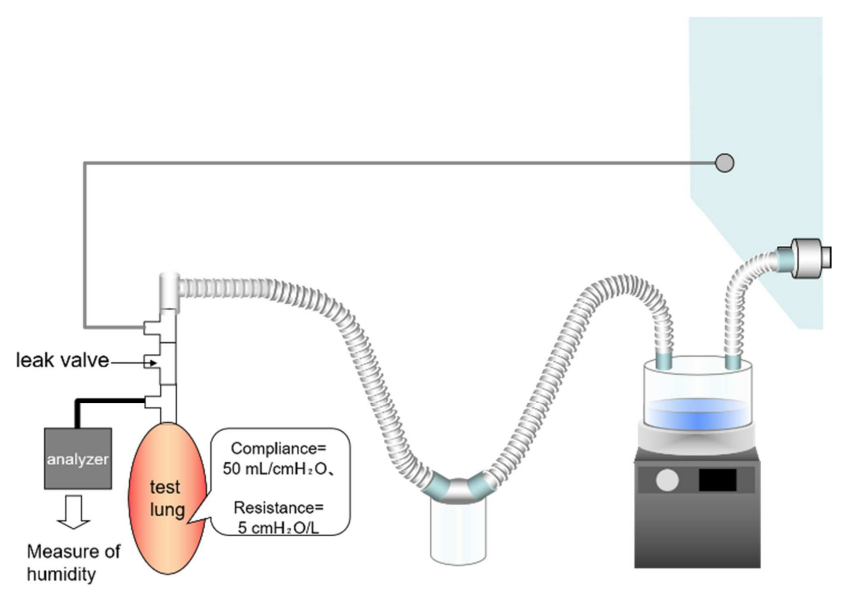

(a)

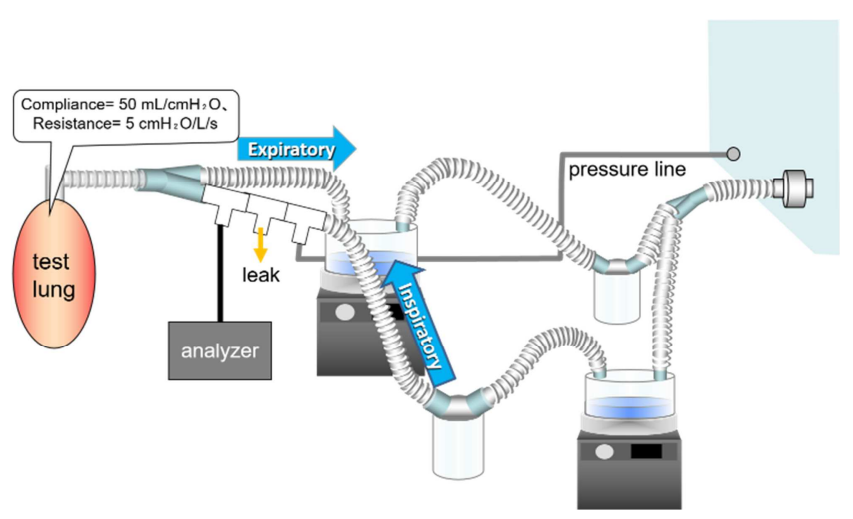

(b)

Figure 1. Experiment setup. (A) Open respiratory circuit with heated humidifier in inspiratory circuit (Setting 1). (B) Both inspiratory and expiratory circuits with heated humidifiers (Setting 2). 


\section{Results}

The mean peak flow in 30 minutes are shown in Table 1. At setting 1, the mean peak flow significantly increased with increasing IPAP $(\mathrm{p}<0.01)$. In addition, leak also was significantly increased the mean peak flow at setting 1 $(\mathrm{p}<0.01)$. At setting 2, IPAP was increased, resulting in increased the mean peak flow $(\mathrm{p}<0.01)$. However, the mean peak flow did not change significantly with leak at setting 2 , indicating differences in leak compensation at setting 1 and 2.

At the beginning of the study the ambient air temperature was $24.6 \pm 0.77^{\circ} \mathrm{C}$, $\mathrm{RH}$ was $63.96 \pm 4.73 \%$, and $\mathrm{AH}$ was $14.41 \pm 1.37 \mathrm{mgH}_{2} \mathrm{O} / \mathrm{L}$. The mean $\mathrm{AH}$ in 30 minutes are shown in Figure 2 and 3. At setting 1 and 2, the mean $\mathrm{AH}$ significantly increased with rising leak. The mean $\mathrm{AH}$ in leak $20 \mathrm{~L} / \mathrm{min}$ was significantly higher than that in leak $60 \mathrm{~L} / \mathrm{min}$ at setting $2\left(27.08 \pm 1.19 \mathrm{mgH}_{2} \mathrm{O} / \mathrm{L}\right.$ in leak $20 \mathrm{~L} / \mathrm{min}$ vs $24.62 \pm 0.59 \mathrm{mgH}_{2} \mathrm{O} / \mathrm{L}$ in leak $60 \mathrm{~L} / \mathrm{min}, \mathrm{p}<0.05$ ) (Figure 3 ). There were no significant differences in the mean absolute humidity with IPAP (data not shown).

\section{Discussion}

We assessed the effect of $\mathrm{AH}$ on leak or flow rate in this study. We measured temperature, $\mathrm{RH}$ and inspiratory flow rate during NPPV. There are leak during NPPV to use open circuit design. We used pressure-limited NPPV in this study. Pressure-limited NPPV controls inspiratory flow rate in the presence of leakage in order to reach IPAP set. The inspiratory flow rate significantly increased with increasing leak or IPAP in this study.

The humidifier is not essential to deliver gas via the upper airway during NPPV [8]. However, non-humidified gas has reason with causing nasal dryness and greater mucosal viscosity. Therefore, we have to consider the need for a heated humidifier according to patient condition. In this study, we measured temperature and $\mathrm{RH}$ with a heated humidifier during NPPV. We calculated $\mathrm{AH}$ with temperature and $\mathrm{RH}$ as $\mathrm{RH}$ was the ratio. In results, $\mathrm{AH}$ reduced with increasing leak. We presumed that warmer humidified gas was discharged through the leak port with increasing flow rate to compensate leak. However, AH was not associated with higher IPAP at the steady leak. This result was not consistent with any other results. The previous study showed both $\mathrm{RH}$ and $\mathrm{AH}$ decreased due to high IPAP in the circuit with the humidifier [11]. Another investigation showed an increase in pressure from $5.1 \mathrm{cmH}_{2} \mathrm{O}$ to $10.2 \mathrm{cmH}_{2} \mathrm{O}$ resulted in lower both $\mathrm{RH}$ and $\mathrm{AH}$ absolute humidity during CPAP [9]. In previous studies, AH was measured in the tube system, which not affected by expired gas. The heated humidifier was included in both inspiratory and expiratory circuits to simulate the physiological lung in this study. The inspired absolute humidity was different in the presence or absence of the heated humidifier into the expiratory circuit. In the report measured humidity inside the mask, $\mathrm{AH}$ was not associated with IPAP [13]. It was consist with our results simulating the physiology. We supposed that expiratory gas was not capable to discharge due to increasing flow rate and might be accumulated into the mask. The expired gas temperature accumulated in the mask might affect the inspired AH. If NPPV users continue to rebreathe, they might cause hypercapnia. Optimal leak volume is necessary to maintain $\mathrm{AH}$ and prevent to rebreathe. NPPV with helmet was improved chronic obstructive pulmonary disease (COPD) with acute exacerbation, but it did not reduce arterial blood carbon dioxide concentration $\left(\mathrm{PaO}_{2}\right)$ [14]. The NPPV with helmet can prevent from pressure ulcer with face mask, but it need higher volume than mask and might rebreathe to minimize leak. Other report showed high IPAP $\left(28 \mathrm{cmH}_{2} \mathrm{O}\right)$ was lower $\mathrm{PaO}_{2}$ than low IPAP $\left(18 \mathrm{cmH}_{2} \mathrm{O}\right)$ in NPPV with mask [15]. We considered that rebreathing may be avoided if only the expired gas passes through the expiratory port.

Table 1. Peak flow of the inspiratory gas various conditions.

\begin{tabular}{llll}
\hline Column1 & IPAP $\left(\mathbf{c m H}_{\mathbf{2}} \mathbf{O}\right)$ & Leak $(\mathbf{L} / \mathbf{m i n})$ & Peak flow $(\mathbf{L} / \mathbf{m i n})$ \\
\hline Setting 1 & 10 & 15 & $37.84 \pm 1.92$ \\
& 15 & 15 & $49.03 \pm 3.54^{\mathrm{a}}$ \\
& 20 & 15 & $69.28 \pm 0.59^{\mathrm{a}, \mathrm{b}}$ \\
& 10 & 60 & $80.70 \pm 9.07^{\mathrm{a}}$ \\
& 10 & 80 & $93.13 \pm 9.18^{\mathrm{a}}$ \\
Setting 2 & 10 & 30 & $28.91 \pm 2.67$ \\
& 15 & 30 & $40.84 \pm 1.79^{\mathrm{c}}$ \\
& 20 & 30 & $50.99 \pm 3.22^{\mathrm{c}, \mathrm{d}}$ \\
& 10 & 20 & $27.05 \pm 1.50$ \\
& 10 & 40 & $32.0 \pm 2.43$ \\
& 10 & 60 & $34.94 \pm 5.28$ \\
\hline
\end{tabular}

${ }^{\mathrm{a}} \mathrm{P}<0.01$ versus IPAP $10 \mathrm{cmH}_{2} \mathrm{O}$ and Leak $15 \mathrm{~L} / \mathrm{min} ;{ }^{b} \mathrm{P}<0.01$ versus IPAP 15 $\mathrm{cmH}_{2} \mathrm{O}$ and Leak $15 \mathrm{~L} / \mathrm{min} ;{ }^{\mathrm{C}} \mathrm{P}<0.01$ versus IPAP $10 \mathrm{cmH}_{2} \mathrm{O}$ and Leak 30 $\mathrm{L} / \mathrm{min} ;{ }^{\mathrm{d}} \mathrm{P}<0.01$ versus IPAP $15 \mathrm{cmH}_{2} \mathrm{O}$ and Leak $30 \mathrm{~L} / \mathrm{min}$.

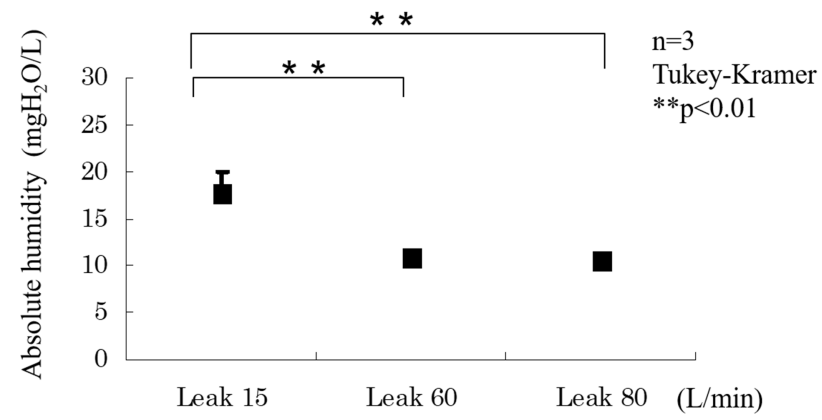

Figure 2. Relationship between AH and leak. at setting 1.

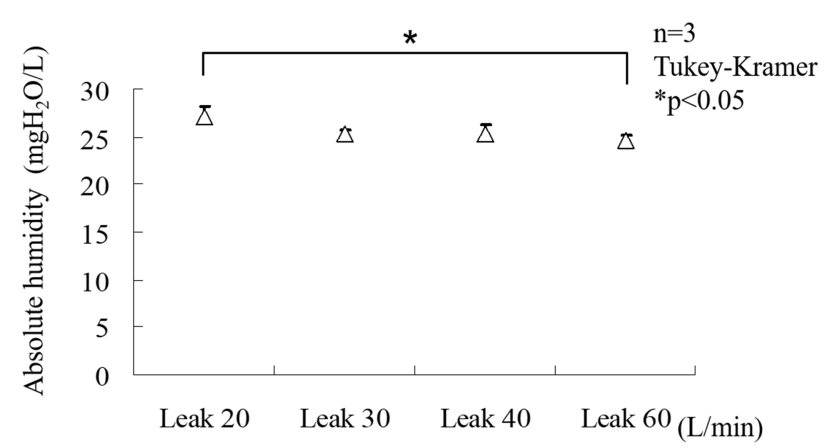

Figure 3. Relationship between $A H$ and leak at setting 2. 


\section{Conclusion}

We showed that $\mathrm{AH}$ reduced significantly with increasing leak, not flow rate. Therefore, AH would depend on leak volume than flow rate. In addition, the inspired absolute humidity related to leak volume and the expired gas temperature in our results. Clinical staff have measured temperature during respirator management, not $\mathrm{AH}$. It is important to evaluate $\mathrm{AH}$ to prevent from dryness and infection.

\section{Acknowledgements}

This work was supported by the special research grants from Himeji Dokkyo University, Hyogo, Japan.

\section{References}

[1] N. S. Hill. "The Worldwide Spread of Noninvasive Ventilation; Too Much, Too Little or Just Right?," Tanaffos, vol. 12, pp. 68, 2013.

[2] T. Kato, S. Suda, and T. Kasai. "Positive airway pressure therapy for heart failure," World J Cardiol 2014, vol. 26, pp. 1175-91.

[3] R. Scala and L. Pisani, "Noninvasive ventilation in acute respiratory failure: which recipe for success?," Eur Respir Rev 2018, vol. 27: 180029 doi: 10.1183/16000617.0029-2018.

[4] S. Yamashita, T. Dohi, K. Narui, and S. Momomura. "Therapeutic efficacy of continuous positive airway pressure in obstructive sleep apnea patients with acute aortic dissection: a case report," J Atheroscler Thromb, vol. 17, pp. 999-1002, 2010.

[5] D. R. Hess. "Patient-ventilator interaction during noninvasive ventilation," Respir Care, vol. 56, pp. 153-65, 2011.

[6] S. Mehta, F. D. McCool, and N. S. Hill. "Leak compensation in positive pressure ventilators: a lung model study,” Eur Respir J, vol. 17, pp. 259-67, 2001.
[7] J. H. Storre, P. Bohm, M. Dreher, and W. Windisch. "Clinical impact of leak compensation during non-invasive ventilation," Respir Med, vol. 103, pp. 1477-83, 2009.

[8] American Association for Respiratory Care, R. D. Restrepo, and B. K. Walsh. "Humidification during invasive and noninvasive mechanical ventilation: 2012," Respir Care, vol. 57, pp. 782-788, 2012.

[9] G. H. Wiest, F. S. Fuchs, W. M. Brueckl, G. Nusko,I. A. Harsch, E. G. Hahn, and J. H. Ficker. "In vivo efficacy of heated and non-heated humidifiers during nasal continuous positive airway pressure (nCPAP)-therapy for obstructive sleep apnea," Respir Med, vol. 94, pp. 364-8, 2000.

[10] Y. Fischer, T. Keck T, R. Leiacker, A. Rozsasi, G. Rettinger, and P. M. Gruen. "Effects of nasal mask leak and heated humidification on nasal mucosa in the therapy with nasal continuous positive airway pressure (nCPAP)," Sleep Breath, vol. 12 , pp. 353-7, 2008

[11] A. E. Holland, L. Denehy, C. A. Buchan, and J. W. Wilson, "Efficacy of a heated passover humidifier during noninvasive ventilation: a bench study," Respir Care, vol. 52, pp. 38-44, 2007.

[12] O. Tetens, "Uber einige meteorologische Begriffe," Zeitschrift Geophysic, vol. 6, pp. 297-309, 1930.

[13] J. Oto, E. Nakataki, N. Okuda, M. Onodera, H. Imanaka, and M. Nishimura. "Hygrometric properties of inspired gas and oral dryness in patients with acute respiratory failure during noninvasive ventilation," Respir Care, vol. 59, pp. 39-45, 2014.

[14] M. Antonelli, M. A. Pennisi, P. Pelosi, C. Gregoretti, V. Squadrone, M. Rocco, L. Cecchini, D. Chiumello, P. Severgnini, R. Proietti, P. Navalesi, and G. Conti. "Noninvasive Positive Pressure Ventilation Using a Helmet in Patients with Acute Exacerbation of Chronic Obstructive Pulmonary Disease: A Feasibility Study," Anesthesiology, vol.100, pp. 16-24, 2004.

[15] J. Lukácsovits, A. Carlucci, N. Hill, P. Ceriana, L. Pisani, A. Schreiber, P. Pierucci, G. Losonczy, and S. Nava. "Physiological changes during low- and high-intensity noninvasive ventilation," Eur. Respir. J, vol. 39, pp. 869-875, 2012. 